\title{
Decarboxylation 2'-dicarboxy-5-(methyl-5'-indolyl-3')- indolyl-3-acetic acid with use of salts of copper
}

\author{
(C) Alexander V. Syromolotov, ${ }^{*}$ Alexander A. Kimyashov, ${ }^{+}$and Sergey V. Sukhorukov \\ Department of Chemical Technology and Computational Chemistry. Chelyabinsk State University. \\ Molodogvardeytsev St., 70b. Chelyabinsk, 454021. Chelyabinsk Region. Russia. \\ Phone:+7 (351) 799-70-64.E-mail: kimyashov@mail.ru
}

\section{*Supervising author; ${ }^{+}$Corresponding author}

Keywords: decarboxylation using quinoline and copper salts, ${ }^{1} \mathrm{H}$ NMR, indolyl acetic acid.

\begin{abstract}
In this article a decarboxylation method based on the use of quinoline with a copper salt is discussed. Decarboxylation is the elimination of $\mathrm{CO}_{2}$ from the carboxylic group of carboxylic acids or the carboxylate group of their salts.

The process is used to produce a large number of organic compounds, such classes as alkanes, alkenes, alcohols, ketones, ethers and esters. Decarboxylation plays an important role in the metabolism of living organisms, namely in the decarboxylation of amino acids. From this we can conclude that the process is important to study.

Decarboxylation proceeds in different ways. The most common methods of decarboxylation includes heating in various conditions. For example, such as heating in the presence of acids and alkalis, under severe conditions with quinoline, thermal oxidation in the presence of transition metal salts, Kolbe reaction. In the procces of the $\mathrm{CO}_{2}$ removal group in relation to amino acids there are several types: $\alpha$-decarboxylation, decarboxylation, associated with the trans-amination reaction and the condensation reaction of molecules.

In the synthesis of substituted auxin 2'-dicarboxy-5-(methyl-5'indolyl-3')-indolyl-3-acetic acid, the yield of the product was not high. The usual heating in the presence of alkali output was less than 5\%, and in this work it was decided to use other methods of decarboxylation to increase the yield of the product.

The aim of the work is to improve the method of decarboxylation of carboxyindolyl substrates for increasing product yield and to compare with the result obtained by ordinary heating of this substances in the presence of alkali.

At the end of the work summed up. Found the optimal conditions for the process of decarboxylation of investigated substrates. Optimal conditions chosen based on product yield. To confirm the chemical structures of the substances, ${ }^{1} \mathrm{H}$ NMR, IR spectroscopy, and elemental analysis were used.
\end{abstract}

\section{References}

[1] R.A. Kolarovič, Z. Fáberová. Catalytic decarboxylation of 2-alkynoic. Journal of Organic Chemistry. 2009. Vol.4. P.7199-7202.

[2] G.B. Jones, B.J. Chapman. Decarboxylation of indole-2-carboxylic acids: improved procedures. Journal of Organic Chemistry. 1993. Vol.58. P.5558-5559.

[3] S. Kobayashi, K. Suioka, H. Nakano. Tero-Kubota analysis of the stable end products and intermediates of oxidative decarboxylation of indole-3-acetic acid by horseradish peroxidase. Biochemistry. 1984. Vol.23. P.4589-4597.

[4] A.V. Syromolotov, A.A. Kimyashov, and S.V. Sukhorukov. Synthesis of 5-(methyl-5'indolyl-3')-indolyl-3acetic acid. Butlerov Communications. 2018. Vol.54. No.6. P.69-73. DOI: 10.37952/ROI-jbc-01/18-54-6-69

[5] I.V. Mikhura, A.A. Formanovsky, M.M. Rumyantseva, and G.A. Borisova. $N$-Ethylamide 3-indolcarboxylic acid derivatives. Butlerov Communications. 2016. Vol.46. No.6. P.71-73. DOI: 10.37952/ROI-jbc-01/16-466-71

[6] T. Cohen, R.A. Schambach. Copper-quinoline decarboxylation. Journal of American Chemical Society. 1970. Vol.92. P.3189-3190. 